\title{
Photography, Video and Emotional Reconstruction of Victims of Armed Conflict
}

\author{
Norman Fajardo Martínez, Andrea del Pilar Pabón Méndez, Diana Sofía Moreno Rojas, Yenny \\ Viviana Rodríguez García
}

\author{
Graphic Communication Technology Program, Corporación Universitaria Minuto de Dios, Colombia \\ Communication Siences-Journalism Faculty, Corporación Universitaria Minuto de Dios, Colombia \\ Development Education Center, Corporación Universitaria Minuto de Dios, Colombia \\ Psycology Program, Corporación Universitaria Minuto de Dios, Colombia
}

\begin{abstract}
Currently in Colombia, Law 1448 or more commonly known as Victims Law, regulates both collective and individual reparation through a variety of processes, ranging from economic compensation and land restitution to issues such as the accompaniment of State in matters of health, education, housing, income generation programs, up to all those actions that may be necessary to restore their dignity, memory, right to the truth and guarantees of non-repetition. Within this emotional recovery strategy, the representation, language, stories and testimonies of victims are part of the process of creating a memory. The image as a symbol fosters sensations and feelings associated with the context of what has been lived, recalling the past and giving it a new meaning from the present. The image serves as a therapeutic facilitator because it allows the individual to connect with their emotions, memories, ideas, people, objects, etc. more intimately. The main objective of this project is evaluate the effectiveness of the use of photographic and video resources in the emotional recovery and social reconstruction of victims of the armed conflict in Colombia.
\end{abstract}

Keywords: photography; video; emotion; reparation; strategy 


\section{$3^{\text {rd }}$ International Conference On Research In HUMANITIES \& SOCIAL SCIENCES}

11-13 September 2020

Brussels, Belgium

\section{Introduction}

\subsection{The Colombian case}

During the last sixty years, the history of Colombia has been marked by the internal armed conflict. Social inequality, unequal distribution of land, and a political class that did not represent the needs of the majority were factors that led to the origin of violence and armed struggle. Then, with the irruption of drug trafficking, narcoterrorism, the presence of new political and armed actors in a context of revolutionary struggle mixed with economic and territorial dominance, the cold war, drug war and the war against terrorism, exacerbated the social and political problems in Colombia. This is how the fracture created by inequalities and the use of violence and the armed struggle for power has marked the political and social dynamics that have taken place in Colombia since the Republic was established (S. XIX) until the present day when the country explores new ways with the current peace agreements.

In this conflict, the civilian population has been affected, surrounded by these disputes, is the main victim of the different victimizing acts derived from the war and perpetrated by the different armed groups. It is necessary to recognize that the violence Colombia had experienced for so many years is not only a sum of facts, victims, or perpetrators. Violence is the result of intentional actions, mainly inscribed in political and military strategies, based on alliances and complex social dynamics. The Historical Memory Group sets as a starting point of the narrative of the armed conflict, the clarification of the dimensions of what happened and when it happened, how and where it happened, who did it, and who suffered it. To face and reject the naturalization of war it is necessary to recognize how the dynamics of violence have characterized the past in Colombia, breaking the vicious circle of habit and justification. (GMH, 2013).

Acts perpetrated by violent groups, such as displacement, dispossession of properties, physical and psychological violence, torture, kidnapping, extortion, forced recruitment of children and adolescents, selective killings and massacres, among others, have led to the loss of dignity and respect for the human condition and the subsequent psychosocial damages of the communities. As a measure to restore their rights, Law 1448 of 2011 establishes integral care, assistance, and reparation measures, referring to the process of group psychotherapeutic intervention for the victim communities, whose purpose is to remedy and resolve the effects resulting from the conflict generated by the groups outside the law.

The Unit for the Victims Assistance and Reparation established in 2013 a strategy to address emotional recovery that is based on 5 premises:

- Expressions of suffering have emerged as a natural response to abnormal events such as those that have occurred in the context of the armed conflict.

- There are a large number of conditions that are found in the development of the personal and social history of the victims, and the acts of violence are just one of the things that have happened to them. In this way, the people affected are not only suffering, but they

\section{www.icrhs.org info@icrhs.org}




\section{Eorhs}

\section{$3^{\text {rd }}$ International Conference On Research In HUMANITIES \& SOCIAL SCIENCES}

11-13 September 2020

Brussels, Belgium

have a number of resources that allow them to face life too, and they must be taken into account for the repair and restoration process.

- We can all do something about the suffering of others. At this point, the importance of guiding work teams in a psychosocial approach of dignity and recognition that avoids the experience that victimizes a person in two or more moments of their life, raising the psychosocial perspective to a fundamental condition of work with human rights.

- Suffering has different forms of expression or symbolization. For example, it may be symbolized in the body of someone who has some physical illness derived from emotional involvement, other times it is symbolized in silence, or anger; that is why the work of emotional recovery can use processes that go to the images with which the understandings of war or suffering have been possible to procure metaphors that allow their representation.

- Representation is what makes recovery easier. That is to say that when the situation is represented, it is put in a public language so that it can be understood both by those who stage it and by those who see it.

According to the World Health Organization (WHO) "the presence of emotional symptoms and mental disorders in the victims of the conflict in Colombia is very high. From the entire population of victims, 63 percent have some form of significant clinical symptoms, and 33 percent meet the criteria for the diagnosis of a mental disorder." (Campo-Arias et al., 2014).

\subsection{The facts in the department of Meta}

The department of Meta is a region where political violence has focused and has many threats, like the uncontrolled growth of the population due to displacement, insecurity, lack of economic opportunities, abandonment of environmental policies, and corruption and drug trafficking that become catalysts for the other problems that afflict the region. All these factors mean that the Meta department does not have adequate economic, social, and political development.

Figure 1: Villavicencio location on the map of Colombia 


\section{iorhs}

\section{$3^{\text {rd }}$ International Conference On Research In}

HUMANITIES \& SOCIAL SCIENCES

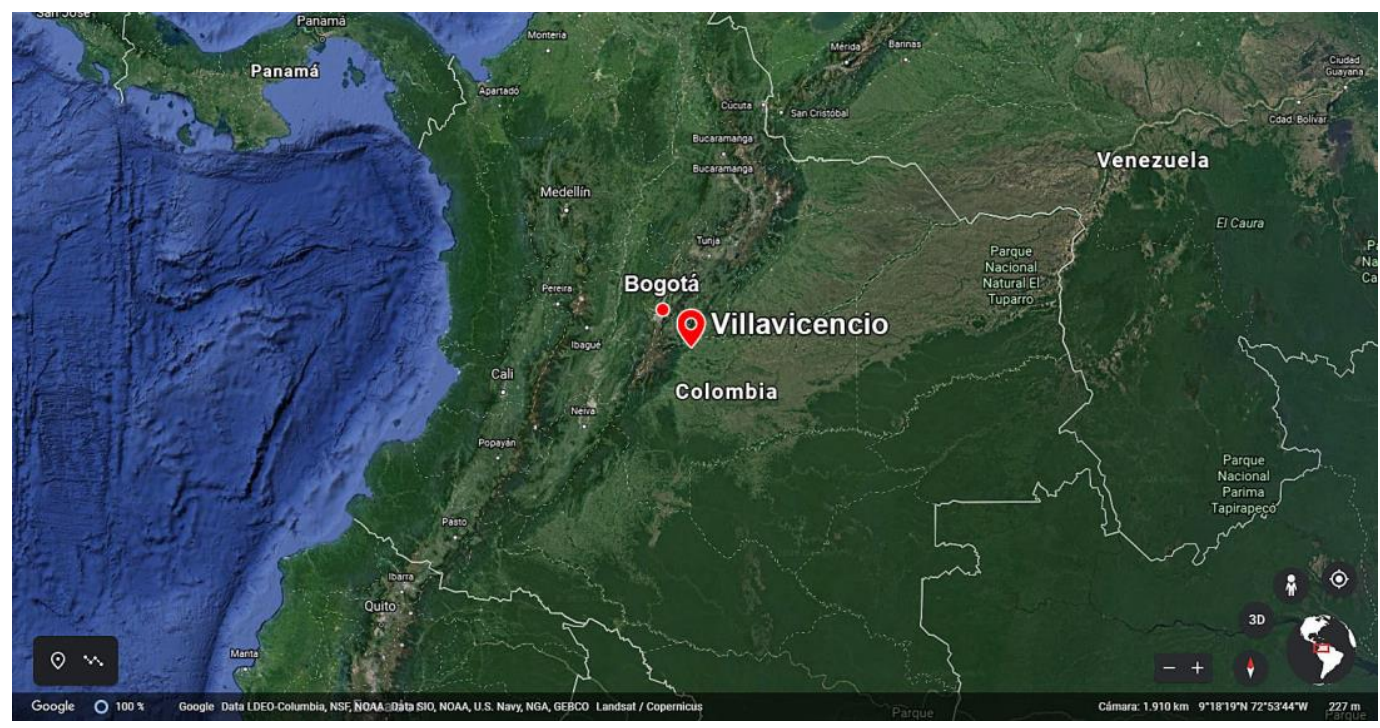

Source: Google Earth, data LDEO-Columbia, NSF, NDAA Data SIO, NOAA, U.S. Navy, NGA, GEBCO Landsat/Copernicus, 2020.

Although the department of Meta is contiguous to Cundinamarca and Villavicencio is the closest capital city to Bogotá, the limited dialogue between the country's political and administrative centre and the Meta region is evident, due to the excessive administrative centralization that has characterized Colombia from its origins in the Republican era.

This isolation also generates institutional fragility, which in turn affects phenomena such as the political exclusion of vulnerable segments of the population, high levels of administrative corruption, lack of opportunities for the inhabitants of Meta to freely and responsibly exercise their political expression beyond of clientelist pressures. Added to this is the territorial dispute exercised by illegal armed groups that have generated displacement, drug trafficking, narcoterrorism, massacres, kidnapping, extortion, forced recruitment, among others (PNUD, 2010).

Of the 248,480 victims registered in the department of Meta, 204,493 are qualified for the emotional recovery process, requiring comprehensive psychotherapeutic actions that allow them their full social integration. Hence the functionality of this project, which aims to analyse the relevance of photography and video resources in the recovery processes. The objective is that victims can comply with the process of acceptance and representation of violent events in the process of emotional rehabilitation. The collective reconstruction of memory is needed to achieve this objective, as well as recognizing all the events that occurred before the victimization process that serve as tools for emotional recovery. For this reason, it is important to recognize how photographic and video resources could be established as therapeutic strategies for social and personal emotional reconstruction.

\subsection{The image in social change}

According to the National Centre for Historical Memory of Colombia (CNMH): 


\begin{abstract}
"During the periods of conflict and post-conflict, the memory and its construction have taken an important place on the work and priorities of a large number of community groups, civil society organizations, victims and survivor groups, and non-governmental organizations. Remembering and narrating the conflict consider the learnings and the multiple dilemmas that emerge from this work. And how to contribute to the tasks of historical clarification and truth, and to dignify the memories of the victims when memory constitutes a critical area. Commemoration and memory construction projects have been included in transitional justice and historical memory processes, as one of the key mechanisms that help societies and groups settle matters with a past of war or massive violence, and advance towards non-violence and non-repetition." (p. 13)
\end{abstract}

The National Centre for Historical Memory proposes the use of photography as a tool for the reconstruction of historical memory.

"The photos (individual and albums) constitute a central cultural object in our management of the memory of the past, and reference points to connect to many possible pasts. Looking at or organizing photos constitutes an act of recognition of the past. When an event (individual, family or community) is captured in a photograph, it becomes part of the event, because, although the experience may have been disorderly or unsatisfactory, the photo will project the appropriate emotions towards the future." (p. 89)

The activities exposed in the project of the National Centre of Historical Memory do not entail a therapeutic accompaniment that allows the subject to carry out a process of resolution and social and psychological rehabilitation. Therefore, it is necessary to identify as the inclusion of photographic and video resources. They can help the process of emotional recovery and reconstruction of the collective memory of victims of the armed conflict in Colombia.

\title{
2. Photography and video in therapeutic processes
}

\subsection{Objetives}

Primary objective.

- Evaluate the effectiveness of the use of photographic and video resources in the emotional recovery and social reconstruction of victims of the armed conflict in Colombia.

Secondary objectives.

- Promote a dynamic of reconciliation in a community victim of the armed conflict through the use of photographic and video resources.

- Describe the implications of the use of photographic and video resources in the therapeutic processes with victims of the armed conflict of a specific population.

- Generate collective memory reconstruction strategies through the use of photographic and video resources. 


\section{$3^{\text {rd }}$ International Conference On Research In HUMANITIES \& SOCIAL SCIENCES}

- Implement audiovisual strategies that generate new tools for the life project of the victims of the armed conflict.

\subsection{Methodology}

Applying a mixed methodology with a concurrent transformative design, with which quantitative and qualitative data are collected at the same time guided by the participatory exercise, this research seeks to evaluate the effectiveness of a therapeutic process based on the use of photographic and video resources in emotional recovery and social reconstruction of a group of victims from Villavicencio, Colombia. The purpose of this methodology is to converge the quantitative and qualitative information, either nesting it, connecting it, or achieving its confluence. Therefore, its strengths and weaknesses are the same as those of the triangulation design or the nested design (Sampieri et al., 2010).

The study uses photographic and video tools within the process of emotional recovery and social reconstruction of the victims of the armed conflict that are living in Villavicencio, Colombia, specifically, the victims of forced displacement and enforced disappearance of the 1997 Mapiripán massacre. The study is developed in four phases:

- Reconciliation Dynamics: In this phase, the population's photographic and video resources are obtained together with the accompanying speech. In this way, the context of the individual and the victimizing fact can be recognized.

- Implications of the use of photographic resources: The phototherapy protocol is applied in this stage. Pretest and posttest measurement of psychological aspects is made, such as social adaptation, anxiety, and psychological wellness of the population. The objective is to measure the impact of the intervention using psychotenic instruments.

- Strategies for the reconstruction of collective memory: Based on the information generated in the first two phases of the project, consists of artistic exhibitions that allow the acknowledgment and acceptance of the facts and promote emotional recovery.

- Audiovisual strategies for life project: With the previously proposed strategies, social unity is generated among the inhabitants and the recognition of these previous situations for their non-repetition.

The project is currently in its first phase. The data has been collected through interviews and audiovisual records focused on photography as a facilitator of the story based on the memory and history of the victim. The intervention protocol for the second phase of the project is under construction.

\subsubsection{Analysis of emotional discourse in exposure to photographs of the subject's memory}

With this strategy of emotional recovery and delving into the representation, the language, the stories and testimonies of the victims are part of the process of creating both individual and collective memory. The use of photographs allows to promote memories in the individual, the image as a symbol helps dialogue between sensations and feelings associated with the context 


\title{
$3^{\text {rd }}$ International Conference On Research In HUMANITIES \& SOCIAL SCIENCES
}

of what has been lived, recalling the past and resignifying from the present (Cubillos Rodriguez \& Quintanilla, 2009).

To recognize the history of the individual, the individual memory, and contribute to the collective memory, the use of the individual's discourse analysis is important. Discourse analysis allows us to read society through the social reality in which each individual is immersed. With this in mind, we want to analyze the discourse and the emotions associated with it through the stories told by victims of the armed conflict in the department of Meta.

To achieve this, it seeks to meet these objectives:

- Collect the testimonies and stories of people who have been victims of the armed conflict.

- Identify the emerging categories associated with emotions that arise from the collected stories.

- Recognize how exposure to photographs affects the subject's speech and the emotions associated with it.

For the discourse analysis, a qualitative paradigm with a narrative design is taken as a methodological framework, where the researcher collects data on the life stories and experiences of certain people to describe and analyze them.

\begin{abstract}
Narrative design on various occasions is a research scheme, but also a form of intervention, since telling a story helps to process issues that were not clear or conscious. It is frequently used when the objective is to evaluate a sequence of events. Likewise, it provides a microanalytical table (Sampieri, Collado, \& Baptista, 2010, p. 504).
\end{abstract}

Informed consent and authorization for the use of the image were used to carry out the semistructured interviews, focused on the subject's previous history. The information was collected through recordings and photographic records of the participants' photographic resources.

A story is obtained about each of the participants, allowing us to get closer to their personal history and have audio records. In these stories, discourse analysis will be carried out, allowing the identification of emotional characteristics that promote the emotional well-being of the participants. For the structuring of the proposed analysis, the structure proposed by Santander (2011) will be used. That structure establishes some categories (conceptual, discursive, linguistic) and concepts (key theoretical and analytical) related to each other and keeping a degree of coherence between them.

Discourse analysis must have a level of appropriate analysis of the context, theory, and analysis. The matrix proposed by Santander (2011) considers the object of study (A), the conceptual categories (B), the discursive categories (C), and semiotic/linguistic categories (D). In the same way, the key theoretical concepts that refer to the general framework of analysis and the analytical concepts in which the analysis methodology is selected. For the research, the matrix was adapted according to the criteria proposed by the author (Figure 2).

\section{www.icrhs.org info@icrhs.org}


Figure 2: Semiotically oriented discourse analysis matrix

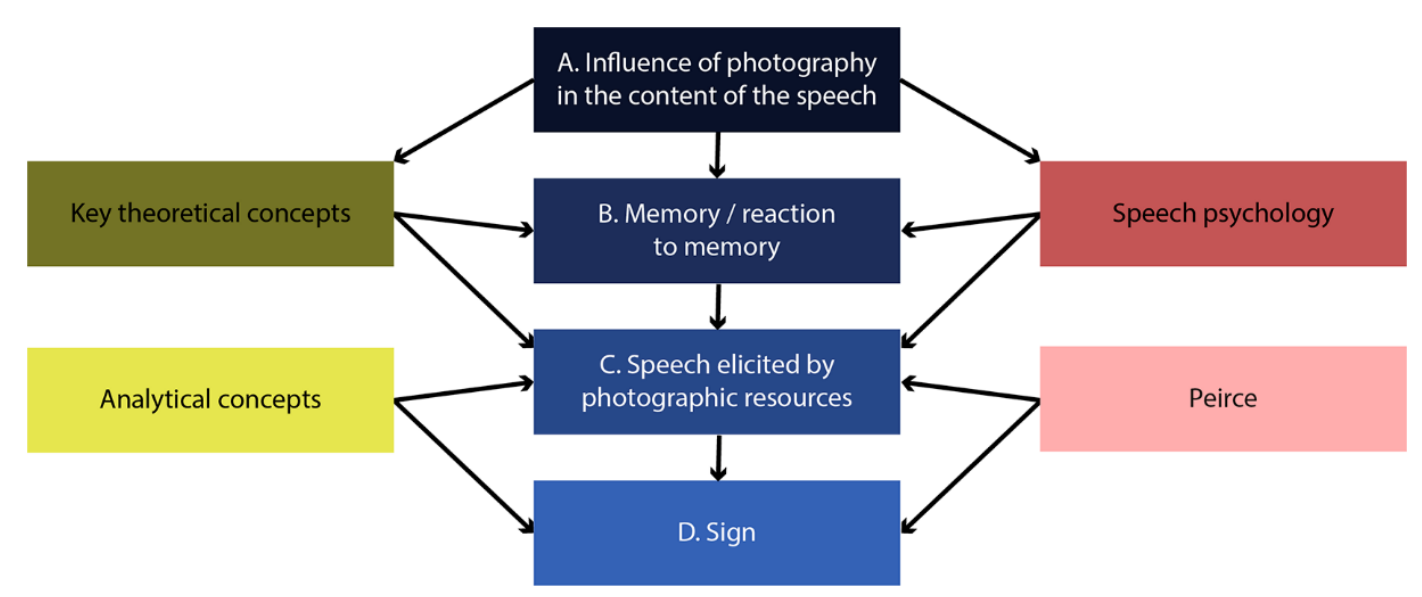

Source: Santander (2011)

\subsubsection{Psychosocial intervention protocol with photographic and video resources}

After the first tests applied to the victims of the municipality of El Dorado, it is intended to apply the tests to the victims who are in the city of Villavicencio, also in the department of Meta, more specifically to those registered in the Unit for Attention and Reparation of Victims, and those belonging to the Association of Displaced Women of Meta (ASOMUDEM). The psychosocial intervention protocol has also been developed with photographic and video elements as therapeutic resources in the emotional recovery of victims of the armed conflict in Colombia. The objective of this protocol is to indicate a methodological guide for the development of emotional recovery activities aimed at the population victim of the armed conflict, establishing guidelines in the use of resources for emotional recovery that guide interdisciplinary teams that carry out intervention psychosocial, identifying the roles, ethical and normative principles that guide the implementation of resources, and proposing the use of psychometric tests that allow monitoring and evaluation of the emotional recovery processes of the population victim of the armed conflict. The ultimate goal pursued is to generate an emotional recovery strategy in victims of the internal armed conflict in Colombia through therapeutic photography, where important moments of the participating population are immortalized, allowing to identify the victims' perception of the past, present, future and the emotions evoked by each moment recorded in them.

The execution activities for the protocol are framed under the principles of the satisfaction measures of the integral repair component, these are assessable under the objectives set for each of the protocol activities, therefore, in planning the interdisciplinary team will do direct reference to such measures and their compliance.

The principles are as follows:

- Dignification of victims: satisfaction measures must make victims visible, enhance or destigmatize.

- Identification of Damage-Measure of Satisfaction: In this sense, the design and, above all, the implementation must start from the identification of the damage caused and the understanding of the situation of the victims and the expectations they have, from a 


\section{$3^{\text {rd }}$ International Conference On Research In HUMANITIES \& SOCIAL SCIENCES}

11-13 September 2020

Brussels, Belgium

process of attentive and supportive listening; understanding that this process involves the resignification of life projects and seeks the realization of their recognition in society as subjects of rights.

- Participation: the satisfaction measures must in any case be decided, agreed upon and specified by the victims.

- Differential and gender approach: satisfaction measures must recognize that different damages have been produced that generate needs for the recognition and restoration of rights that are also different, in accordance with the particularities (age, sexual orientation, gender identities, ethnic, rural, urban areas, among others) of the people and population groups affected.

- Sustainability: the satisfaction measure designed must take into account technical, financial and social sustainability so that it can be truly effective.

- Meaning: raising awareness in society in general (local, regional or national) about the significance of the satisfaction action carried out to generate solidarity and public awareness for non-repetition.

- Socialization: it must be promoted by its public, wide and massive dissemination. Public outreach in itself can be considered a measure of satisfaction. The public dissemination that is made should try to reach all sectors, to socialize and sensitize the entire society.

(Unit for Attention and Reparation of Victims, 2019)

This protocol will be ruled by the provisions of Law 1090 of 2006 that regulates the exercise of the profession of psychology, dictating the Code of Ethics, Bioethics and other provisions, governed by articles 2, 15, 16 and 23 of this same Law (2006).

This protocol has been designed in principle for the Victims, who According to Law 1448 of 2011 ARTICLE 3: "VICTIMS. Victims are considered to be those persons who individually or collectively have suffered damage due to events that occurred since January 1, 1985, as a consequence of violations of International Humanitarian Law or of serious and manifest violations of international Human Rights standards, which occurred with occasion of the internal armed conflict [...]" (Ministry of Interior and Justice, Government of Colombia, 2011).

The Health and Psychosocial Care Program for Victims of the Armed Conflict (PAPSIVI in Spanish), which arose as ordered in article 137 of Law 1448 of 2011 (Ministry of Health and Social Protection, 2017), is aimed at providing care in emotional recovery as negative consequences to the events potentially through which victims of the internal armed conflict in Colombia have passed, thus counting on the support of health professionals and human talent trained to provide health support to the victims.

Therefore, this protocol will be a guide for an interdisciplinary team that wants to generate bets for psychosocial care for victims of the internal armed conflict, in this case it is important to clarify that those who make up the psychosocial team have an interest in fostering spaces of recognition of the other, considering the diverse characteristics of the population, enabling social integration and health care, guaranteeing the promotion of self-realization and human dignity. Emphasis is placed on the fact that the team formed is made up of people with knowledge of crisis care, group intervention, and interests in art therapy and the like. The present protocol is interested in the use of photography as a therapeutic resource in the

\section{www.icrhs.org info@icrhs.org}




\section{iorhs}

$3^{\text {rd }}$ International Conference On Research In HUMANITIES \& SOCIAL SCIENCES
11-13 September 2020

Brussels, Belgium

emotional recovery of the population victim of the internal armed conflict, and a comprehensive intervention is proposed from a psychosocial approach that allows the overcoming of emotional discomfort and promotes the social integration of the victims.

This protocol is aimed at professionals who are part of the following fields and, in turn, functions and competencies that are related to each of them are established.

- Health Sciences

- Social and Human Sciences

- $\quad$ Arts and Humanities

Figure 3: Interview with one of the victims of violence in the municipality of El Dorado, Meta.

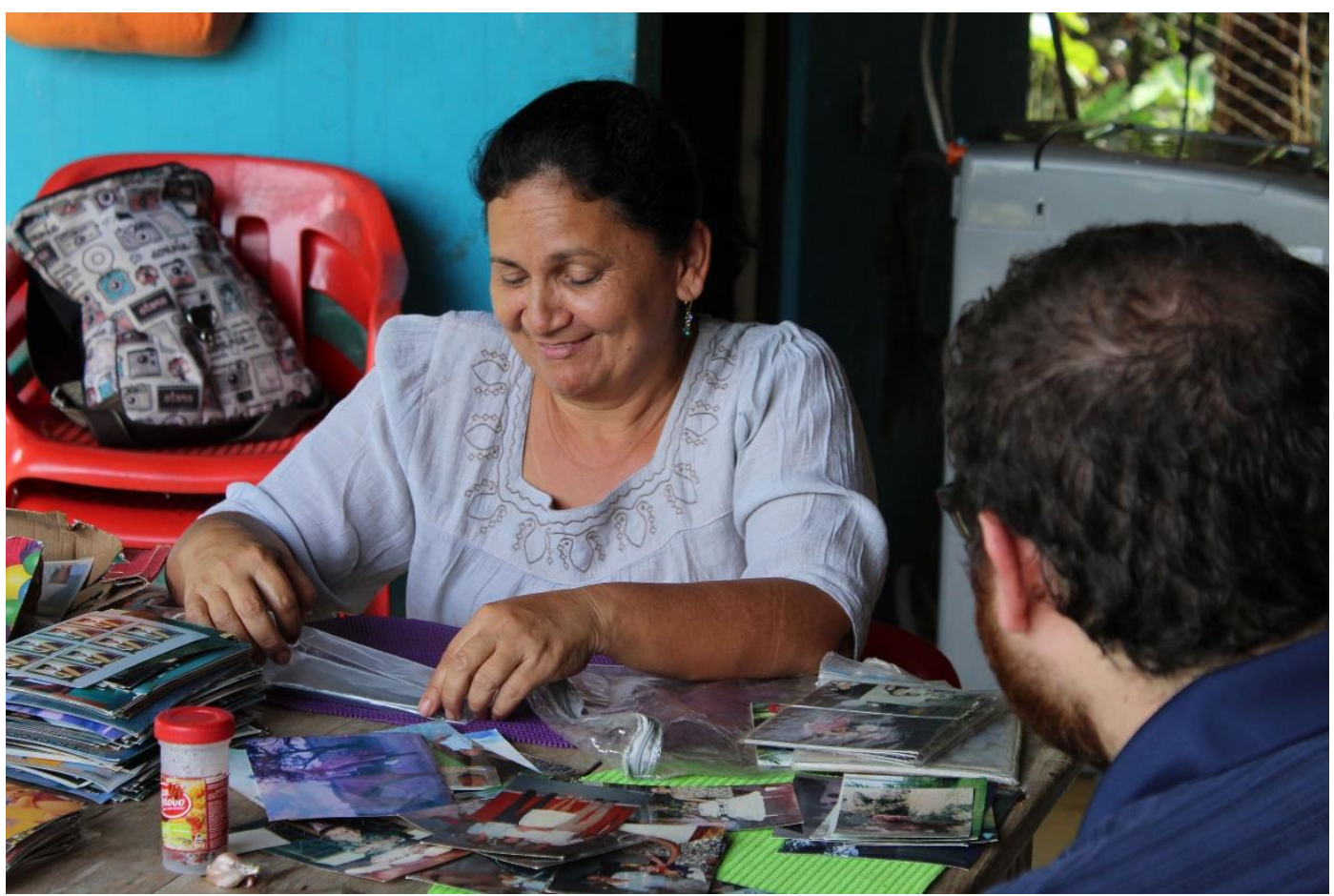

Source: Own authorship (2019)

\section{Health Sciences}

Within the field of Health Sciences, the preference is chosen for psychologists and psychiatrists who, from a psychosocial approach, will have skills in psychological first aid, crisis intervention, and evaluation and intervention for emotional and psychological disorders. (Ministry of Health and Social Protection, 2017).

This protocol works with victims of internal armed conflict and under the supervision of Psychologists, these according to their professionalism have specific functions for the development of different activities, based on the Protocol of health care - Papsivi (Ministry of Health and Social Protection, 2017) being these:

- Assessment of the person victim of the armed conflict, from a psychosocial perspective. 


\section{$3^{\text {rd }}$ International Conference On Research In HUMANITIES \& SOCIAL SCIENCES}

- Identification of risks of possible psychological effects.

- Intervention in psychological first aid in cases where it is required.

\section{Social and Human Sciences}

From the field of Social and Human Sciences, there are professionals in law, economics, sociology, anthropology, communication, among others; with whom it is sought to generate dynamics and strategies that accompany the victims of the internal armed conflict, and as mentioned (Correa, 2009). The function of the social and human sciences must be directed to interpret the social, cultural and economic environment.

In general, the following functions should be taken into consideration for each of the aforementioned fields:

- Conflict resolution and mediation function

- Function of social order and organization

- Promotional function

- Guidance for the optimal use of resources

- Organization and creation of companies

- Systematization function

\section{Arts and Humanities}

From the field of Art and Humanities, there is a preference for professionals, photographers, graphic, video and graphic design communicators, the latter referred to as graphic documentalist, a professional who performs an informant function and who carries out an activity of management and transmission of knowledge in the field of companies, institutions and organizations. (Vigil, 2013) these professionals will be in charge of keeping a record of the material collected during the meetings that are scheduled with the population that is part of the protocol.

Functions of the graphic documentalist:

- Identification and recognition of photographs

- Media identification

- Conservation and restoration protocols

- Analysis and description

- Content reading

- Description systems

- Application

- Selection of photos

- Edition of the originals

- Diffusion 


\section{$3^{\text {rd }}$ International Conference On Research In HUMANITIES \& SOCIAL SCIENCES}

11-13 September 2020

Brussels, Belgium

- Image publications

- Product visibility

On the other hand, it is necessary to clarify that human talent personnel and professionals who are not part of health must have, according to (Ministry of Health and Social Protection, 2017) knowledge in psychological first aid, crisis intervention, early intervention, resilience, adherence to comprehensive health care, coping strategies, comprehensive care for victims of the armed conflict, as well as validation strategies, normalization of emotional responses and reduction of stigma.

\subsection{Results}

Five previous interviews were conducted with victims of violence in the municipality of El Dorado, Meta, of which only in one of them the main objective of the study was obtained, allowing to inquire about the participant's previous history with the help of the photographs as facilitators of the construction of discourse.

Despite the fact that the research proposed to recognize the previous history not related to the victimizing event, the possible appearance of discursive effects was taken into account (Iñiguiez-Rueda, 2003), these discursive effects are related to any critical emotional event generated by the interactional development of the speech, for this, the interview team was made up of a professional in psychology, a professional in social communication and journalism, and students in professional practice of psychology and social communication and journalism.

The contextual analysis was carried out based on the argumentative repertoires, these are defined as the variation of a topic of conversation based on local demands and interaction. The usefulness of these is based on allowing to identify how the speaker approaches conversations and define plans through the strategic placement of topics (Iñiguiez-Rueda, 2003).

\section{Conclusions}

This Research, which is at the beginning of its second phase, allows us to recognize the importance of photographic and video tools in the process of emotional recovery of the victims of the armed conflict, providing an additional tool so that it can be used not only as a psychotherapeutic process but also as a process of social reconstruction in which the memory of the conflict is recognized as an important event within the social development of the community and additionally to promote the use of these artistic resources for the development of new economic and tourist alternatives for the population. It includes within the repair processes activities that promote both emotional recovery and the construction of the social fabric of the target population, generating a reconstruction of the collective memory of the population through the collection and generation of photographic and video products that serve both for the process of emotional recovery and for strengthening the social fabric of the community.

Also, in the process, it has integrated the investigative activities of psychology and social communication-journalism and graphic communication, promoting the use of relevant resources within the development of the social communication and graphic comunication

\section{www.icrhs.org info@icrhs.org}




\section{$3^{\text {rd }}$ International Conference On Research In HUMANITIES \& SOCIAL SCIENCES}

11-13 September 2020

Brussels, Belgium

within the therapeutic and emotional rehabilitation processes of the psychology, allowing the resources obtained to have a plurality of use in different aspects of the social reconstruction of vulnerable populations, and in the same way facilitating the expansion of knowledge and approach of the reality of the population to the country.

In the development of the intervention protocol, it is necessary to recognize the norms that govern the psychosocial accompaniment of the population victim, since from the legal recognition of people as victims of the internal armed conflict, they are identified as subjects of special protection and priority attention (Sentence T-045 of 2010, Sentence 169 of 2019, Colombia), for which some recommendations and specific parameters are given for their attention and guarantee of rights.

The importance of considering the principle of differential approach has also been discovered, which recognizes that there are populations with particular characteristics due to their age, gender, sexual orientation, and disability status. For this reason, the measures for humanitarian aid, assistance, and reparation established in the law must have such an approach.

In understanding the psychosocial damage of victims, although there have been few studies on the prevalence of mental health impairment, it has been recognized that psychosocial impairment does not necessarily translate into categories of injury or sequelae, and not only It is understood from the meanings of the disease or psychopathology. Therefore, the mechanisms, programs, and action plans must be adjusted to attending to the various psychosocial damages of the victims that characterize the different expressions of suffering and not only those that are experienced as diseases.

\section{References}

[1] Campo-Arias, A. Oviedo, C. and Herazo, E., (2014). "Prevalence of Mental Symptoms, Possible Cases and Disorders in Victims Displaced by the Internal Armed Conflict in Colombia: A Systematic Review," Revista Colombiana de Psiquiatría, vol. 43, pp. 180181.

[2] Centro Nacional de Memoria Histórica, (2013). Recordar y narrar el conflicto: herramientas para reconstruir la memoria histórica. Imprenta Nacional de Colombia, Colombia: Bogotá.

[3] Correa, A. M. (2009). "La investigación en Ciencias Sociales y Humanas bajo el esquema del modelo universidad-empresa-estado, una mirada desde la teoría crítica de la sociedad," Revista Interamericana de Bibliotecología, vol 32, no 2, pp. 231-252.

[4] Cubillos Rodriguez, E. and Quintanilla, O. (2009). Las posibilidades de la fotografía social como estrategia de interacción, intervención e investigación social con niños, niñas y jóvenes víctimas del conflicto armado en Colombia. Procceeding of XIX Latin American Seminar of Schools of Social Work. Guayaquil, Ecuador, pp. 1-13. Available: http://www.ts.ucr.ac.cr/binarios/congresos/reg/slets/slets-019-294.pdf

[5] GMH, (2013). ¡Basta ya! Colombia: Memorias de guerra y dignidad. Imprenta Nacional, Colombia: Bogotá. 


\section{iorhs}

\section{$3^{\text {rd }}$ International Conference On Research In}

HUMANITIES \& SOCIAL SCIENCES

[6] Iñiguez Rueda, L. (2003). El análisis del discurso. Manual para las ciencias sociales. Editorial UOC, España: Barcelona, pp. 83-124.

[7] Ministry of Health and Social Protection (2017). Protocolo de Atención Integral en Salud con Enfoque Psicosocial a Víctimas del Conflicto Armado. IEEE Trans. Minsalud [Online]. Available:

https://www.minsalud.gov.co/sites/rid/Lists/BibliotecaDigital/RIDE/DE/PS/Protocolo-deatencion-integral-en-salud-papsivi.pdf

[8] Ministry of Interior and Justice, Government of Colombia. (June 2011) Ley 1448 del 10 de junio de 2011, por la cual se dictan medidas de atención, asistencia y reparación integral a las víctimas del conflicto armado interno y se dictan otras disposiciones. IEEE Trans. Unidadvictimas [Online]. Available:

https://www.unidadvictimas.gov.co/sites/default/files/documentosbiblioteca/ley-1448-de2011.pdf

[9] PNUD, (2010). Meta: Análisis de la conflictividad. Impresol Ediciones Ltda, Colombia: Bogotá.

[10] Sampieri, R., Collado, C. and Baptista, M., (2010) Metodología de la investigación. 5th ed. Mc Graw Hill, Mexico: Mexico D.F.

[11] Santander, P. (2011). "Por qué y cómo hacer Análisis de Discurso", Cinta moebio, vol. 41, pp. 207-224.

[12] Unit for attention and Reparation of Victims (September 2019) Metodología para la estrategia de reparación integral convivencia y paz. IEEE Trans. Unidadvictimas [Online]. Available:

https://www.unidadvictimas.gov.co/sites/default/files/documentosbiblioteca/4511metodol ogiaparalaestrategiadereparacionintegralconvivenciaypazv2.pdf

[13] Vigil, J. M. (2013). "La Documentación Fotográfica," Revista General de Información y Documentación, vol 6-1, pp 161-193. 